\title{
Context - Driven Antonyms in Political Discourse
}

\author{
Anahit Hovhannisyan ${ }^{1, *}$ \\ ${ }^{1}$ Department of the English Language and Literature, Gyumri State Pedagogical Institute after Mikael Nalbandyan, \\ Gyumri, Republic of Armenia \\ *Correspondence: Department of the English Language and Literature, Gyumri State Pedagogical Institute after \\ Mikael Nalbandyan, Gyumri, Republic of Armenia. E-mail: a_hovhannisyan@mail.ru
}

Received: July 29, 2015 Accepted: November 2, 2015 Online Published: March 6, 2016

doi:10.5430/wjel.v6n1p8 URL: http://dx.doi.org/10.5430/wjel.v6n1p8

\begin{abstract}
In the frame of this article an attempt is made to bridge pragmatics and context-driven antonyms. As a pragmatic approach it focuses on the ways in which antonym relations are derived in contexts of use, particularly in political discourse. In the speeches of an orator an author gives birth to an opposition that functions as an antonymic pair only in the given context dictated by the intention of the speaker. Word pairs that are not branded as antonyms at paradigmatic level work as antonyms only in that situation, having a persuasive mission. However, context-driven antonyms live only on the crossroad of vertical and horizontal relations. For revealing their emphatic function, contextual antonyms are studied in relation to opposition and are defined as subtypes of binary, private opposites.

In speeches of political leaders contextual antonyms obtain quite a new calling; to justify his/ her positions, to gain confidence, to touch the feelings of the audience and to make the speech much more argumental.
\end{abstract}

Keywords: pragmatics; political discourse; opposition; marked/unmarked member of the opposition; vertical antonymic pair; horizontal antonymic pair

\section{Introduction}

Though antonymy has been the subject of continual linguistic scrutiny, yet it is recognized as the most robust of the lexico-semantic relations. One of the "biggest questions are:

In what sense is the term antonym used? Is antonymic pair an opposition? If so, what brings life to it? What kind of opposition is it? What's the marked difference between its opponents?

Before studying antonyms and their functions, one has to decide, whether to use the term antonym in its broad or narrow sense. In its broad sense, antonymy covers a wide range of word pairs expressed by different part speech categories as long as these words expressed are opposite of each other. In the narrow sense, however, antonymy is a relation that holds between a small number of adjective-adjective pairs only (Lyons 1968, Cruse 1986). The widest approach is taken in this paper.

\subsection{Antonymy and Opposition}

To reveal the essence of antonymy it is necessary to turn to opposition. Why opposites? Because the two concepts opposition and antonymy have got the same status in philology, interchangeably circulating in various linguistic studies. And before getting to the backbone of our research we have to pin down the essence of these notions for choosing a workable term - an axis around which are studies will revolve.

Some linguists such as John Lyons and Alan Curse (1986) hold the view that the term antonym should apply only to a specific type of semantic opposition, i.e. involving gradable opposites. In contrast to the position held by Lyons (1968) and Cruse, it is clear that Ruth Kempson (1977), thinks of antonymy from the opposite standpoint; she describes what she calls simple binary opposition; what Lyons calls "ungradable opposition". There is a link between the technical term antonymy and the universally recognized concept of "opposites". The terms opposites and antonyms are used interchangeably and antonyms are supposed to be a specific sub-class of opposites.

I hold the view that the antonymy is a subtype of binary opposition. For proving it we should dwell upon the markedness. 
Firstly, the members of the opposition are supposed to have two types of features: common and differential as any grouping of words is based upon similarities and contrasts. Secondly, one member of the opposition is characterized by the presence of certain different feature, while the other is characterized by the absence of this feature. The first member is called marked (or strong or positive) and the second member - the unmarked (weak or negative). Thirdly, marked or negative (weak) member is of less functional frequence; its functional appearance is limited. Let's consider the following antonymic pair high-low. They make an opposition due to the common meaning that brings them into one entity; they both deal with the same scale of dimension running between two poles or extremes. On the other hand, the marked member of the opposition has pertained a positive feature that is characterized as a distinctive one. Another criterion of markedness is that the unmarked member (low) can generally appear in a wider range of syntactic contexts; in particular, the marked antonym can generally occur with measure phrases, but an unmarked one usually cannot, so we can say "Some of the waves are 15 feet high" (Macmillan: 673), but not " 15 feet low". Similarly we can say High School but never Low School, or high winds (Macmillan: 673) as "very strong", but not low winds or "that was a low trick" (as unfair) and dishonest (Macmillan: 674), but never "that was a high trick". As we can see the above mentioned opposition lives on two clear - cut roots - root antonyms (or absolute, or proper). Absolute antonyms are words regularly contrasted as homogenous sentence members connected by copulative, disjunctive or adversative conjunctions, or used in parallel conjunctions (Arnold: p193). Whenever a sentence contains an antonym or an antonymic pair, it implicitly or explicitly contains comparison. However, the important point to notice is the denial of the one member of antonymic opposition does not always imply the assertion of the other; when we say young it does not always imply old.

Derivation can also play a role in markedness: in pairs where one antonym is derived from the other, is said to be marked (pleasant - unpleasant). It is the derivative affix that makes two words antonyms and they are termed as derivational antonyms. The affix in them serves to deny the quality stated in the stem.

There are typical prefixes and typical patterns that go into play in forming these derivational antonyms.

The regular type of derivational antonyms contains negative prefixes: dis-/-il/-in/ir and so on. Other negative prefixes perform this negative function only occasionally.

"As to the suffixes, it should be noted that modern English gives no examples of words forming their antonyms by adding a negative suffix, such as, for instance, -less. The group is not numerous and in most cases, even when the language possesses words with the suffix- less, the antonymic pairs found in actual speech are formed with the prefix un- .Thus, the antonymic opposition is not selfish: :selfless but selfish:: un selfish" ( Arnold: p 196).

We have coined a new term for derivational antonyms - defective. They are defective in relation to root antonymic pairs; In the semantic range of non-absolute antonyms the two opponents of the antonymic pair have much in common and differ only in one seme, whereas in root antonyms the scope of differential semantic features is greater.

Worthy of note are also antonyms of triple opposition, where reigns a blending of root and defective antonymic pairs. Thus in the triad small - medium - large we have got two types of antonyms: root and defective. The root antonymic pair small - large is intertwined with the two defective antonymic pairs: small-medium -large

In relation to opposition defective antonymic pair can be defined as private binary type of opposition.

Binary as the opposition is two-membered; the number of members correlated is two and private as one member of the opposition (positive) is characterized by a distinctive feature which lacks the second constituent (negative). Whereas root/ proper or absolute antonymic pairs are polar members of a gradual opposition which may have intermediary elements, the actual number of which may vary from zero to several units, e.g. beautiful-pretty-nice-ugly.

The difference between root and derivational antonyms is not only morphological but semantic as well. To determine its essence we should turn to logic. These notions when contrasted are classified into contradictory or contrary notions. Contradictory notions are mutually opposed, denying one other, e.g. happy-unhappy. Contrary notions are also inconsistent but in a different way. "If some notions can be arranged into a series according to increasing difference in one of their qualities the most distant elements of series will be classed as contrary notions, e.g. young:: old in the series young::middle- aged:: old " ( Arnold: p 197). Therefore derivational antonyms may be characterized as contradictory and root antonyms - as contrary.

\subsection{Paradigmatic and Syntagmatic Antonyms}

It's a well acknowledged fact that antonym canonicity is the degree to which antonymous words are entrenched in memory and conventionalized as pairs in language.

It is important to differentiate between the antonym canon of a language and the antonym canon of an individual. 
Antonyms are parts of the language's canon if they are fixed as antonyms in dictionaries. Since they measure frequency of co-occurrence, they are more likely to treat as canonical pairs that have more common words and senses.

A word can have also multiple antonyms but only one of them is considered to be "the more marked, the more living". For instance if you ask someone for the opposite of "short", they are most likely to say "long", without considering that "short" is not the antonym of "long" in its "rude, unfriendly" sense She is very busy and can be a little short at times Macmillan: p 136). It follows that antonyms are capable of creating different paradigms.

Canonicity in the individual refers to the context-driven or non-canonical antonyms which are not fixed as antonyms in dictionaries; they function as antonyms only in a particular context. Since they measure less frequency of co occurrence, they are most likely to have very limited semantic range.

If we try to define these two phenomena in reference to systemic relations of language than canonical antonymic pairs are to be defined as paradigmatic as they exist between elements of the system outside the strings where they occur in contrast to syntagmatic relations that exist only in a certain context, i.e., paradigmatic are vertical and syntagmatic are horizonted relations by their very nature.

Paradigmatic and syntagmatic antonymic pairs have different distribution from semantic standpoint. Unlike paradigmatic antonymic pairs in the frame of which the two members of the opposition are equally charged in semantics (good-bad), in syntagmatic antonymic oppositions one of the members of the opposition has more extreme value than the other as: good-awful

To study the properties of antonymic pair at syntagmatic level means to study them in their linear distribution. Here poses another significant question seeking for an urgent answer: why do some words of the same linguistic environment tend to create antonymic pairs and the others not. Undoubtedly, context plays a dominant role; a status of a conductor in an orchestra who directs the roles among the musicians. But semantic potential of a word plays the role of the first violin in this orchestra. In a definite context due to its semantic potential and due to its paradigmatic relations a word gains a dependent status, making a new opposition. This newly- born antonymic pair lives only in the current use as a concrete modification of abstract vertical relations.

\section{Methodology}

Theoretical background is based on the pragmatic approach to lexical semantic relations, according to which these relations constitute a part of our metalinguistic knowledge (Murphy: 2003).

One of the first analyses of antonymy making use of corpus data was done by Mettinger, who showed that "contrast is a phenomenon showing greater regularity than has hitherto been assumed" (Mettinger: 1994, 46)

Arnold succeeds in proving that the difference between absolute and derivational antonymic pairs is semantic (Arnold: 1973).

I have also adapted for local purposes the methodology of analyzing antonyms in relation to oppositions, proposed by Arnold (Arnold: 1973).

\section{Semantic - Pragmatic Traits of Context-Driven Antonyms}

As a pragmatic approach it focuses on the ways in which antonym relations are derived in contexts of use, offering ample evidence that antonym choice is context-sensitive.

Politics as discourse is a constantly redefined area. David Bell says that "We are all political beings in our everyday life" (Bell, 1975:10) and adds that: "if politics is communication, we must study who talks to whom and what they say".

Political discourse is peppered with numerous non- canonical antonyms.

Besides different language means and stylistic devices a very powerful technique (antonymy) is widely used by orators to make deep influence on the audience, to gain confidence, to convince the listeners that the interpretation given by the speaker is the only correct one.

Pragmatically estimated, context - driven antonymic pairs are called to perform a new mission in political discourse, i.e., persuasive function. A strong impact on the audience presupposes presence of figurative language. It turns into a figure of speech with bright shades of coloring.

The non - canonical antonyms are studied in the speeches of different American presidents of various times, so as to see whether the time has got its imprint on the function of antonymic pairs in political discourse. 
Throughout the speeches of the presidents of the United States of America we come across a number of non- canonical antonym pairs which are not fixed as antonyms in dictionaries:

* The man who does nothing cuts the same sordid figure in the pages of history, whether he be a cynic, or fop, or voluptuary “(Citizenship In A Republic. Theodore Roosevelt, April 23, 1910).

The main mission of non- canonical antonyms here is to show that every man creates his history, his fate and everybody should live in a way that his name be remembered and be saved in the leaves of history.

* "Character must show itself in the man's performance both of the duty he owes himself and of the duty he owes the state" (Citizenship In A Republic. Theodore Roosevelt, April 23, 1910).

Every person is a part of society, a part of the country he lives in, and besides the duties which he owes to himself and family, every member of the society has some duties to his country as well.

* "But let me say, with respect to other countries, that I am wholly opposed to the Catholic or Protestant, to compel, prohibit, or persecute the free exercise of any other religion" "II believe in an America Where the Separation of Church and State is absolute". John F. Kennedy, September 12, 1960).

Kennedy states that the most serious issues of the election were not religious and assured his audience that his Catholic faith would not impact on his public live. Freedom of religion is considered by many people and nations to be a fundamental human right. Religion should not interfere with politics.

* "Human identity is no longer defined by what one does, but by what one owns. But we have discovered that owing things and consuming things does not satisfy our longing for meaning. We've learned that piling up material goods cannot fill the emptiness of lives which have no confidence or purpose" ("Crisis of Confidence." Jimmy Carter, July 15, 1979).

Here the president infers that materials dominants in American life. A materialistic person is someone who has a preoccupation with the owning of material possessions and equates them to happiness and fulfillment. But owning something and consuming something won't make people happy.

* "We've got to stop crying and start sweating, stop talking and start walking, stop cursing and start praying" ("Crisis of Confidence". Jimmy Carter, July 15, 1979).

In the above sentence the role of context- driven autonyms is to state that the government should stop talking and start acting. Actions speak louder than words. And people should stop cursing and start trusting their government again.

* "And while it's hard to hear yourself called deceitful and manipulative, I remember Ben Franklin's admonition that our critics are our friends, for they do Show us our faults". ("I Am Profoundly Sorry". Bill Clinton, December 11, 1998). If we define critics as people who criticize you (find fault with uncover errors), that means that they help you to correct those errors (you can't correct them unless you know about them). Then we can accept (without starting a discussion on what exactly friends are) that people who help us are our friends. It follows that critics are our friends.

* "The children of this country can learn in a profound way that integrity is important and selfishness is wrong, but God can change us and make us strong at the broken places" (I Have Sinned". Bill Clinton, September 11, 1998).

Integrity is the quality of being honest and having strong moral principles; moral uprightness. In this context, integrity is the inner sense of "wholeness" deriving from qualities such as honesty and consistency of character, besides it refers to the unity of the United States of America. The word "selfishness of a person who is in the habit of not giving others enough consideration. The same refers to the president of the country. He should never be selfish.

"We'll help the emerging democracies of Iraq and Afghanistan so they can grow in strength and defend their freedom" (Victory Speech. George W. Bush. November 3, 2004).

The ongoing conflicts in Iraq and Afghanistan have taken a tremendous tell on the people of those countries. The decade long war in Afghanistan has continued to take lives with each passing year. As of February 2014, at least 21.000 civilians are estimated to have died violent deaths as a result of this war.

In Iraq, over 70 percent of those who died of direct war violence have been civilians. So it is of vital importance for these countries to step wars and gain freedom. Moreover, the USA will give these countries a helping hand.

* "It's the answer spoken by young and old, rich and poor, Democrat and Republican, black, white, Latino, Asian, Native American, gay, straight, disabled and not disabled - Americans who sent a message to the world that we have never been a collection of Red States and Blue States. We are, and always will be, the United States of America" (Election Victory Speech. B. Obama, 4 November, 2008). 
America is the place where a man from Africa or Asia, Christian or Muslim can become the leader of the country. That this could and did happen re-defines what the nation is. This made Obama not only popular, as measured by the election results, specifically among all groups who have been excluded from full participation in the American dream, or feel so exclude: black and browns, Latinos and Asians Jews and Muslims, and youth and women, disabled - not disabled. It also has made him popular around the globe: more popular in many nations, than their own leaders, a "brand" that many up - and - coming - politicians seek to be associated with. He has presented a very attractive American face to the world.

Red states and blue states refer to those states of the United States whose residents predominantly vote for the Republican (red) or Democratic Party (blue) presidential candidates. The colors red and blue are also part of the colors of the U.S. flag.

* "... We honor them not as makers of war, but as wagers of peace". (Nobel Lecture. B. Obama, 10 December.2009)

Peace requires responsibility, peace entails sacrifice. The verb "to wage" presupposes an activity to be carried on, an action (usually a campaign or war).By using "peace" as an argument of such a predicate, he bends its meaning, which no longer can be considered as state of affairs, or as an "absence of conflict". Throughout this move the orator introduces as a metaphorical and paradoxical expression.

In the speeches of the president proper or root antonymic pairs are intertwined with context-driven, non-canonical antonyms.

"There is also one rule that lies at the heart of every religion-that we do unto others as we would have them do onto us. This truth transcends nations and people -a belief that isn't new; that isn't black or white or brown; that isn't Christian or Muslim or Muslim or Jew".

Here Barack Obama uses both canonical and non- canonical antonymic pairs: black/white, white/brown, Christian /Muslim, emphasizing that no matter what colour your skin is or what religion you belong to, you are a human being and you have equal rights. Through this crucial device, Barack Obama evokes specific images, creating memorable mental pictures in the audience.

Those already quoted will suffice to illustrate both the linguistic essence of proper antonyms and their pragmatic impact.

\section{Conclusion}

To sum up, human thinking and languages are closely related and the significance of antonymy in human thinking is inevitably reflected in human language. Human beings have a general tendency to polarize experience and judgment to think in opposites. And this would explain the existence of a large quantity of antonyms in the vocabulary of human languages. Describing antonyms in terms of maximal similarity and minimal difference means that words have different antonyms in different contexts depending on which of the words' properties are most relevant to contrast within a particular context use. Antonyms are never used arbitrarily but with a purpose. Context driven antonyms pairs are often used in political speeches to achieve rhetorical effects. Antonymy is a powerful technique used by orators to achieve their desired effect, that is persuasion. While horizontal antonym is variable i.e. context dependent, particular antonymic pairs are often canonical in that they are known without reference to context and can be labeled as invariants.

\section{References}

Arnold I.V. (1973). The English Word. Moscow "Visshaya shkola".

Bell D. (1975). The Revolution of Rising Entitlements. Fortune.

Cruse D Alan. (2000). Lexical Semantics. Cambridge University Press.

Cruse, D. A. (2000). Meaning in Language: An Introduction to Semantics and Pragmatics. Oxford: Oxford University Press.

Kempson, R.M. (1971). Semantic Theory (Cambridge Textbooks in Linguistics). Cambridge University Press.

Lehrer, A., \& Lehrer, K. (1982). Antonymy. Linguistics and philosophy, 5(4), 483-501. http://dx.doi.org/10.1007/BF00355584

Lyons. (1968). Introduction to theoretical linguistics. Cambridge: Cambridge University Press. 
http://dx.doi.org/10.1017/CBO9781139165570

Macmillan English Dictionary. (2002). Macmillan Education.

Mettinger, A. (1994). Aspects of Semantic Opposition in English. Oxford: Clarendon.

Murphy, M.L. (2003). Semantic Relations and the Lexicon. Cambridge University Press. http://dx.doi.org/10.1017/cbo9780511486494 